\title{
Substantiation of the rock massif permeability based on packer tests
}

\author{
Georgii Neuvazhaev ${ }^{1, *}$, and Alexandr Rastorguev ${ }^{1}$ \\ ${ }^{1}$ Nuclear Safety Institute of the Russian Academy of Sciences, 115191 Moscow, Russia
}

\begin{abstract}
There are uncertainties, concerning the hydraulic properties used in groundwater flow models while constructing them. This article shows the ranges of changes in hydraulic properties and their optimization for a groundwater flow model in a heterogeneous geological environment of the Nizhnekansky massif.
\end{abstract}

\section{Introduction}

Flow and transport in fractured rock is of high scientific interest because of ongoing research in several countries as part of their development of nuclear waste repositories in cristalline rocks[1,2,3] Hydrogeological modeling is an important part of the process of justifying the long-term safety of radioactive waste deep geological disposal facilities. Modern numerical models take into account a large number of factors, corresponding to individual characteristics and processes, and accordingly require the specification of a large number of input parameters. Not all of these parameters are known with sufficient accuracy in advance; some of them require additional field or laboratory studies, others contain inevitable uncertainties due to limitations of measurement methods or their natural variability.

In this work we consider the determination of hydrogeological characteristics of elements of geological structure of the Nizhnekansky massif in the Krasnoyarsk region on the basis of modeling and calibration of the hydrogeological model.

\section{Simulation problem statement and results}

The Nizhnekansky massif is located at the junction of two large structures of the West Siberian and East Siberian plates. The study of the site began 10 years ago, wells were drilled to depths of $700 \mathrm{~m}$, packer tests with interval pressure measurements and single pumping tests were carried out. In this paper we used data on hydrogeological wells, where regular interval tests were performed every $50 \mathrm{~m}$.

Here we solve a steady state groundwater (GW) flow problem in confined conditions using the data available for the site of the potential placement of deep geological disposal in Nizhnekansky massif [4]. In order to build a geological cross-section, data from surveys were used, which was the basis of the GW flow model with the selection of elements of the

\footnotetext{
*Corresponding author: neyvazhaev@ibrae.ac.ru
} 
geological structure. The hydraulic conductivity coefficients were set within their own range for each of the elements of the geological structure. Experimental data obtained during the pumping tests were used as observation data. For four wells 35 points with known pressures were obtained [4].

The boundary conditions for the model were set in the following way:

1. The right border was drawn along streamlines ending on the Shumikha River ( the streamlines from the hydrodynamic point of view are the impermeable boundaries);

2. The lower boundary of the model corresponded to no-flow boundary condition due to the fact that the rocks that lie at the mark $-350 \mathrm{~m}$ are treated as impermeable;

3. On the upper boundary the rainfall recharge rate was set to $0.00001 \mathrm{~m} / \mathrm{day}$, except for the Shumikha River on which Dirichlet-type boundary condition with the level of $331 \mathrm{~m}$ was set.

4. Two types of boundary conditions were considered to choose the most applicable at the left border: a) Dirichlet-type boundary condition with constant hydraulic $400 \mathrm{~m}$ head, obtained on the basis of water level measurements.b) Newmann - type boundary condition on the left boundary. The flow rate was selected during the model calibration.

The parameters and ranges of variation are shown in Table 1. Figure 1 shows the simulated profile. To solve the two-dimensional groundwater flow problem, a nonorthogonal discretization by triangular prisms and finite volume method were used. In order to take into account the heterogeneity shown in Figure 1, it was necessary to use 26218 cells with sides ranging from $10 \mathrm{~m}$. The simulation was performed using the GeRa software [5]. For optimization problem Cuckoo Search algorithm was used [6,7], it has proved its applicability for hydrogeological problems' optimization. Comparison of calculated and observed data for the two boundary conditions options on the left boundary is shown in Figures 2 and 3. The smallest value of the object function was achieved with the Dirichlet boundary conditions, although the option 2 is more physically justified. Perhaps it is due to the fact that the second option has more parameters for optimization. Parameters obtained as a result of optimization are presented in Tables 1-2.

Table 1. Parameter variation ranges of the profile flow model with Dirichlet-type condition on the left boundary. Objective function $=1660$.

\begin{tabular}{|l|c|c|}
\hline \multicolumn{1}{|c|}{$\begin{array}{c}\text { Geological structure } \\
\text { element }\end{array}$} & Variation range & Final value \\
\hline \multicolumn{3}{|c|}{ hydraulic conductivity [m/day] } \\
\hline Quaternary sediments & $\left(1.0 \cdot 10^{-3}-5.0 \cdot 10^{-1}\right)$ & 0.1 \\
\hline Crust of weathering & $\left(1.0 \cdot 10^{-3}-5.0 \cdot 10^{-1}\right)$ & 0.1 \\
\hline Fissured dikes & $\left(1.0 \cdot 10^{-6}-3.5 \cdot 10^{-2}\right)$ & 0.012 \\
\hline Gneiss & $\left(1.0 \cdot 10^{-6}-1.0 \cdot 10^{-3}\right)$ & 0.0009 \\
\hline Fissured gneiss & $\left(5.0 \cdot 10^{-3}-1.0 \cdot 10^{-1}\right)$ & 0.005 \\
\hline Crushed rocks & $\left(1.0 \cdot 10^{-2}-1.0\right)$ & 0.57 \\
\hline Dikes & $\left(1.0 \cdot 10^{-6}-1.0 \cdot 10^{-2}\right)$ & 0.0005 \\
\hline
\end{tabular}




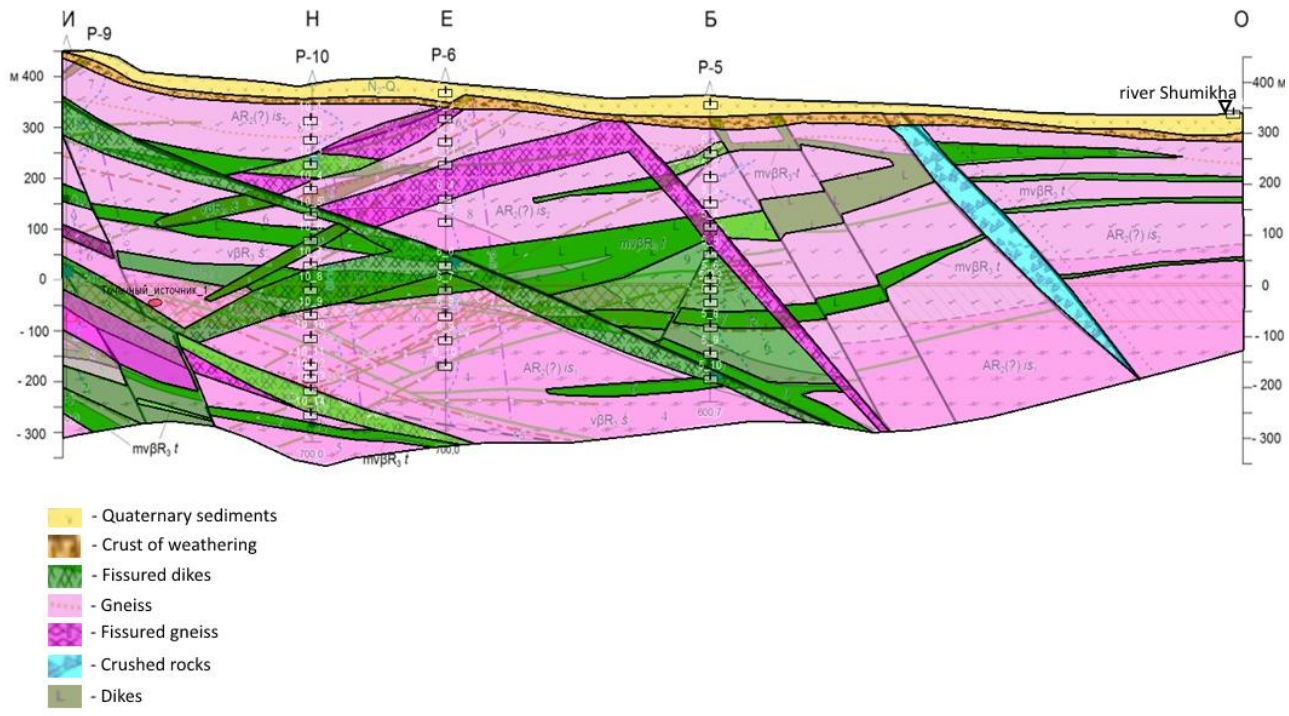

Fig. 1. Schematic geological cross-section of the modeling area and legend.

Table 2. Parameter variation ranges of the profile flow model with Neumann-type condition on the left boundary. Objective function $=2021$.

\begin{tabular}{|l|c|c|}
\hline \multicolumn{1}{|c|}{$\begin{array}{c}\text { Geological structure } \\
\text { element }\end{array}$} & Variation range & Final value \\
\hline \multicolumn{3}{|c|}{ hydraulic conductivity [m/day] } \\
\hline Quaternary sediments & $\left(1.0 \cdot 10^{-3}-5.0 \cdot 10^{-1}\right)$ & 0.082 \\
\hline Crust of weathering & $\left(1.0 \cdot 10^{-3}-5.0 \cdot 10^{-1}\right)$ & 0.43 \\
\hline Fissured dikes & $\left(1.0 \cdot 10^{-6}-3.5 \cdot 10^{-2}\right)$ & 0.025 \\
\hline Gneiss & $\left(1.0 \cdot 10^{-6}-1.0 \cdot 10^{-3}\right)$ & 0.005 \\
\hline Fissured gneiss & $\left(5.0 \cdot 10^{-3}-1.0 \cdot 10^{-1}\right)$ & 0.031 \\
\hline Crushed rocks & $\left(1.0^{-1} \cdot 10^{-2}-1.0\right)$ & 0.0009 \\
\hline Dikes & $\left(1.0 \cdot 10^{-6}-1.0 \cdot 10^{-2}\right)$ & 0.0006 \\
\hline \multicolumn{3}{|c|}{ water flow [m3/s] } \\
\hline $\begin{array}{l}\text { Quaternary sediments and } \\
\text { Crust of weathering }\end{array}$ & $\left(1.0 \cdot 10^{-3}-1.0 \cdot 10^{-7}\right)$ & 0.0001 \\
\hline Gneiss & $\left(1.0 \cdot 10^{-3}-1.0 \cdot 10^{-7}\right)$ & 0.00033 \\
\hline Dikes & $\left(1.0 \cdot 10^{-3}-1.0 \cdot 10^{-7}\right)$ & \\
\hline
\end{tabular}

\section{Conclusion}

To conclude, we would like to note that according to the results obtained during the simulation, the GW flow model gives an adequate match of the field data after calibration. Breeds of dikes of various fracture density have lower hydraulic conductivity than gneisses. Poorly fractured dikes can be considered as barriers. For dikes and gneisses there is a direct link between the hydraulic conductivity and the fracture index. 


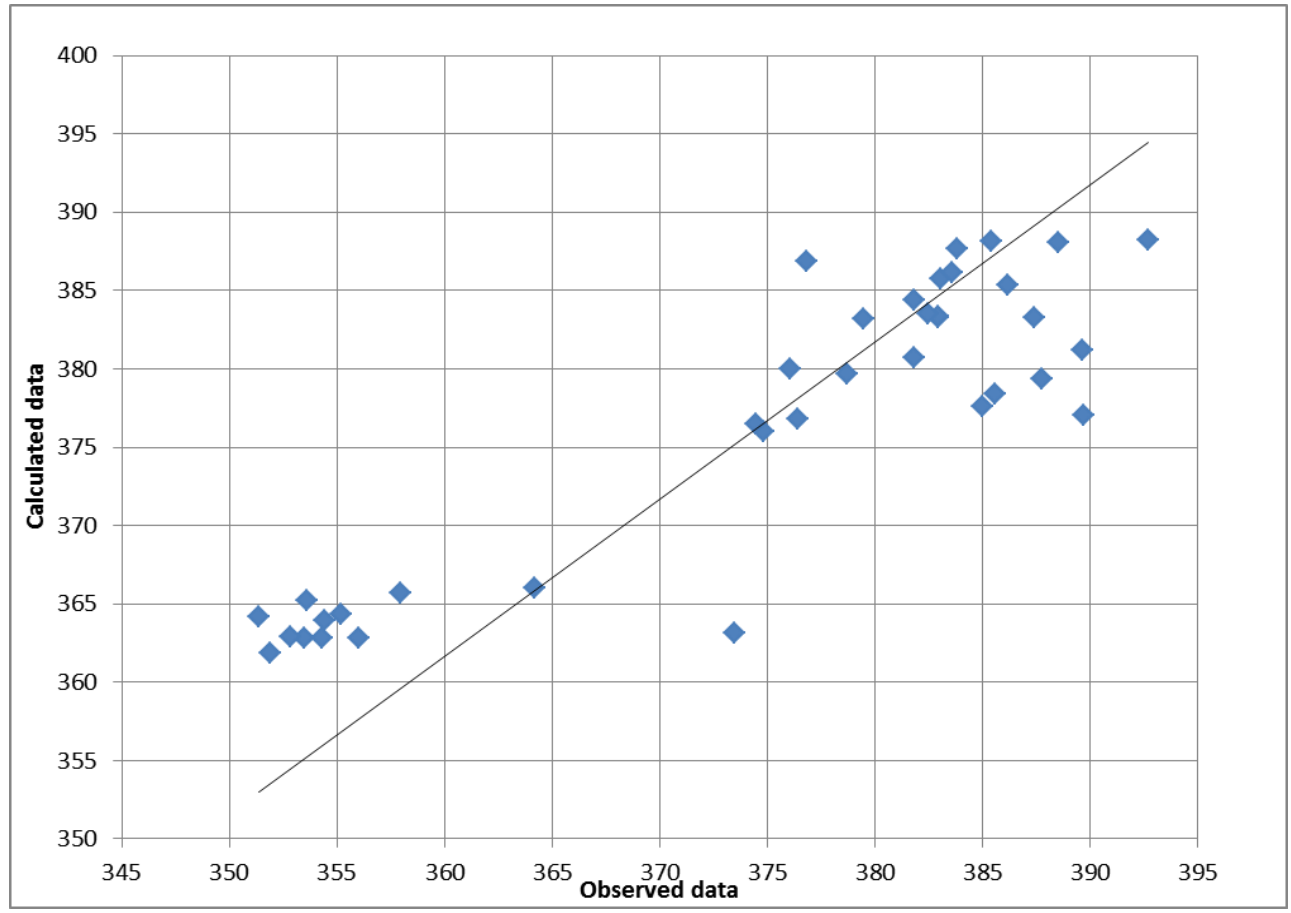

Fig. 2. Comparison of observed and calculated data (scatter plot) for Dirichlet-type boundary condition on the left boundary. Objective function $=1660$.

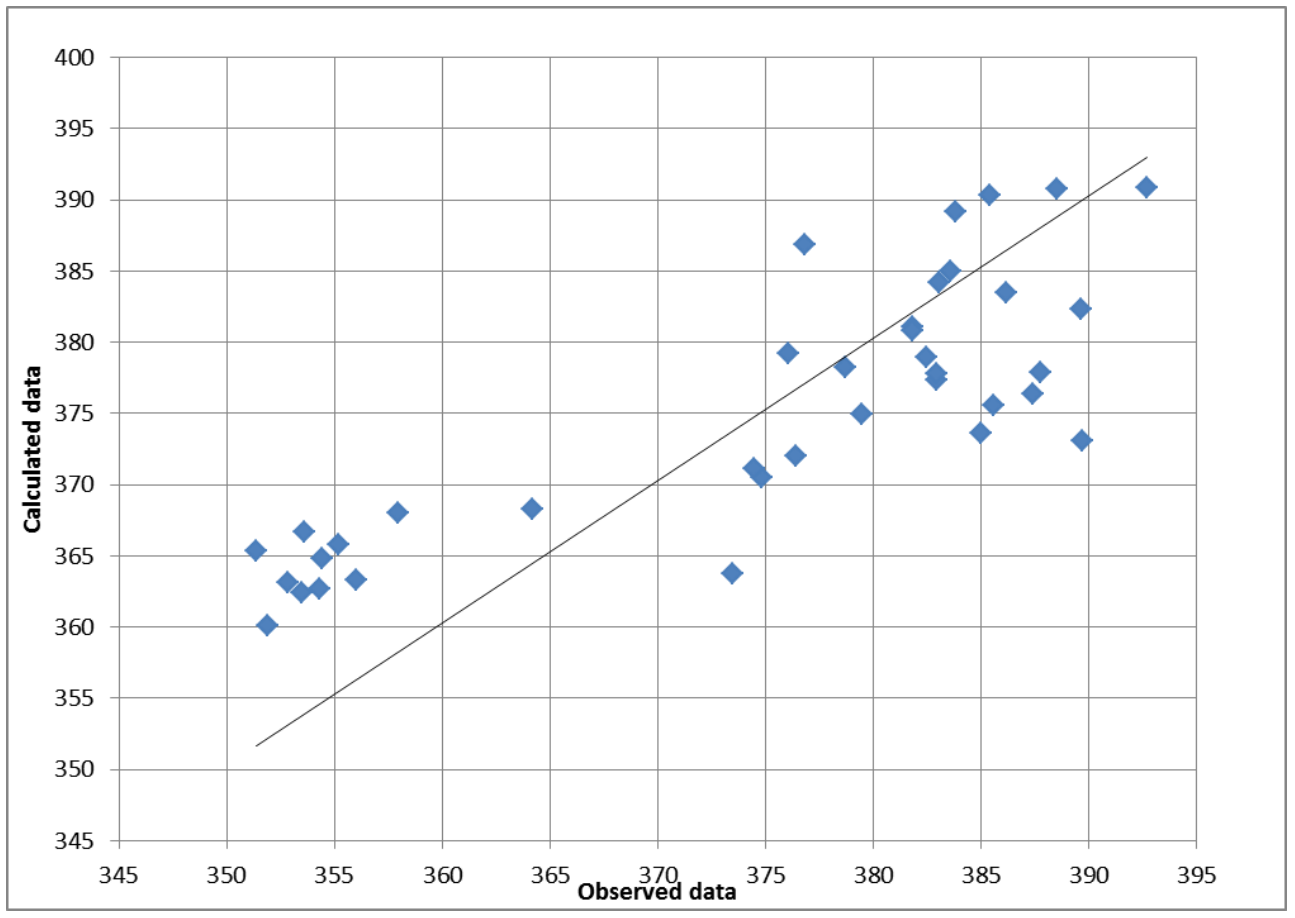

Fig. 3. Comparison of observed and calculated data (scatter plot) for Neumann -type condition on the left boundary. Objective function $=2021$. 


\section{References}

1. B. Berkowitz, Characterizing flow and transport in fractured geological media: a review. Adv Water Resour, 25, 861-884 (2002)

2. S. Neuman, Trends, prospects and challenges in quantifying flowand transport through fractured rocks. Hydrogeol J 13:124-147 (2005)

3. C.F. Tsang, I. Neretnieks, Y. Tsang, Hydrologic issues associatedwith nuclear waste repositories. Water Resour Res 51. doi:10.1002/2015WR017641 (2015)

4. A.Yu. Ozersky, / A.Yu. Ozersky, K.A. Zablotsky. Krasnoyarsk, Krasnoyarskgeology OJSC, (2011)

5. I. Konshin, I. Kapyrin, Scalable Computations of GeRa Code on the Base of Software Platform INMOST. Lecture notes in computer science, 10421. V. Malyshkin (Ed.): PaCT 2017, 433-445 (2017)

6. Mostafa Khajeh, Elham Jahanbin, Application of cuckoo search optimization algorithm-artificial neural network method of zinc oxide nanoparticles-chitosan for extraction of uranium from water samples, Chemometrics and Intelligant laboratory Systems, 135, 70-75 (2014)

7. Daya Gupta, Bidisha Das, V.K. Panchal, Applying Case Based Reasoning in Cuckoo Search for the Expedition of Groundwater exploration, Advances in Intelligent Systems and Computing, 201, 341-355 (2012) 